\title{
Uji Efek Antifungi Ekstrak Daun Biduri (Calotropis Gigantea L.) Terhadap Pertumbuhan Jamur Trichophyton Mentagrophytes
}

\author{
Safrida, Rosa Mardiana*, Nurul Husna \\ Program Studi D-III Farmasi, Akademi Farmasi YPPM Mandiri, Banda Aceh, Indonesia \\ Email: rosa29mardiana@gmail.com
}

\begin{abstract}
Abstrak-Daun biduri (Calotropis gigantea L.) merupakan salah satu tanaman yang dapat digunakan sebagai antifungi. Daun biduri dijadikan sebagai antifungi berdasarkan zat kimia yang terdapat didalamnya seperti tannin, saponin flavonoid dan polifenol. Jamur Trichophyton mentagrophytes dapat menyebabkan penyakit kulit yang ditandai dengan timbulnya bercak melingkar dan bersisik atau gelembung kecil yang dikenal dengan istilah Tinea atau kurap. Jamur ini memiliki habitat (terutama pada daerah yang beriklim tropis dan basah) di tanah, manusia dan hewan. Penelitian ini bertujuan untuk mengetahui efektifitas ekstrak daun biduri (Calotropis gigantea L.) dalam menghambat pertumbuhan jamur Trichophyton mentagrophytes dan untuk mengetahui berapakah konsentrasi optimal ekstrak daun biduri (Calotropis gigantea L.) untuk menghambat pertumbuhan jamur Trichophyton mentagrophytes. Penelitian ini dilakukan di Laboratorium Mikrobiologi Fakultas Tarbiyah UIN Ar-Raniry dan Laboratorium kimia FKIP kimia Universitas Syiah Kuala Banda Aceh pada tanggal 26 April sampai 21 Agustus 2018. Daun biduri diekstraksi dengan menggunakan metode maserasi yang direndam selama 5 hari dengan 2 kali pengulangan dan diuapkan dengan menggunakan alat rotary evaporator hingga memperoleh ekstrak sebanyak $30 \mathrm{ml}$ berwarna hijau kehitaman dan kental. Uji daya hambat terhadap jamur Trichophyton mentagrophtes dilakukan dengan metode difusi disc difussion pada media Potato Dextrose Agar (PDA) dengan konsentrasi 20\%, 35\% dan 50\%. Antifungi ketoconazole yang dibuat dalam bentuk suspensi sebagai kontrol positif dan aquadest sebagai kontrol negatif. Hasil penelitian menunjukkan bahwa diameter zona hambat yang diperoleh dari ekstrak daun biduri pada konsentrasi 50\% sebesar 9,16 mm termasuk dalam kategori sedang, pada konsentrasi $35 \%$ sebesar 8,66 mm termasuk dalam kategori sedang, konsentrasi $20 \%$ sebesar 8,16 mm termasuk dalam kategori sedang, pada ketoconazole suspensi sebesar $11,83 \mathrm{~mm}$ termasuk dalam kategori kuat dan pada aquadest sebesar $0 \mathrm{~mm}$ yang tidak memiliki daya hambat.
\end{abstract}

Kata Kunci: Uji Daya Hambat, Trichophyton Mentagrophytes, Daun Biduri (Calotripis Gigantean L).

\begin{abstract}
The leaf of biduri (Calotropis gigantea L.) is one of the plants that can be used as antifungal. Biduri leaves are used as antifungals based on the chemicals contained in them such as tannins, flavonoid saponins and polyphenols. The fungus Trichophyton mentagrophytes can cause a skin disease characterized by the appearance of circular and scaly patches or small bubbles known as Tinea or ringworm. This fungus has a habitat (especially in tropical and wet climates) in soil, humans and animals. This study aims to determine the effectiveness of biduri leaf extract (Calotropis gigantea L.) in inhibiting the growth of the fungus Trichophyton mentagrophytes and to determine what is the optimal concentration of biduri leaf extract (Calotropis gigantea L.) to inhibit the growth of the fungus Trichophyton mentagrophytes. This research was carried out at the Microbiology Laboratory of the Tarbiyah Faculty of UIN Ar-Raniry and the Chemical Laboratory of the Chemical Science Faculty, Syiah Kuala University, Banda Aceh, from 26 April to 21 August 2018. Biduri leaves were extracted using the maceration method which were soaked for 5 days with 2 repetitions and evaporated with using a rotary evaporator to obtain extract as much as $30 \mathrm{ml}$ blackish green and thick. Inhibition test against the fungus Trichophyton mentagrophtes was carried out using the disc diffusion method on Potato Dextrose Agar (PDA) media with concentrations of $20 \%, 35 \%$ and $50 \%$. Ketoconazole antifungal was made in suspension form as a positive control and aquadest as a negative control. The results showed that the diameter of the inhibition zone obtained from biduri leaf extract at a concentration of $50 \%$ of $9.16 \mathrm{~mm}$ was included in the medium category, at a concentration of $35 \%$ of $8.66 \mathrm{~mm}$ was included in the medium category, 20\% concentration of $8.16 \mathrm{~mm}$ was included. in the medium category, $11.83 \mathrm{~mm}$ of ketoconazole suspension was included in the strong category and $0 \mathrm{~mm}$ of aquadest which had no inhibitory power.
\end{abstract}

Keywords: Inhibitory Test, Trichophyton Mentagrophytes, Biduri Leaf (Calotripis Gigantean L).

\section{PENDAHULUAN}

Di Indonesia, penyakit infeksi merupakan masalah utama dalam bidang kesehatan, terutama infeksi kulit. Kulit merupakan bagian tubuh manusia yang cukup sensitif terhadap berbagai macam penyakit. Penyakit kulit biasanya disebabkan oleh banyak faktor. Di antaranya, faktor lingkungan dan kebiasaan hidup sehari-hari. Lingkungan yang sehat dan bersih akan membawa efek yang baik bagi kulit. Demikian pula sebaliknya, lingkungan yang kotor akan menjadi sumber munculnya berbagai macam penyakit.

Menurut Indrayatna (2010), penyakit kulit adalah penyakit infeksi yang paling umum terjadi pada orang dari segala usia. Sebagian besar, pengobatan infeksi kulit membutuhkan waktu lama untuk menunjukan efek. Salah satu penyakit kulit yang disebabkan oleh jamur adalah penyakit kurap. Ada banyak jenis jamur yang biasanya menyerang manusia dan beberapa di antaranya dapat menginfeksi kulit, kuku dan rambut. Salah satu jamur penyebab penyakit kurap adalah jamur Trichophyton mentagrophytes, yaitu jamur yang menyerang kulit kaki manusia.

Dalam istilah medis, kurap disebut sebagai Tinea atau infeksi dermatofit atau dermatofitosis. Walaupun kurap bukan penyakit yang mematikan, namun adanya kurap sangat mengganggu dan akan mengurangi rasa percaya diri 
Journal of Pharmaceutical and Health Research

Vol 2, No 1, Februari 2021, pp. 8-11

ISSN 2721-0715 (media online)

DOI 10.47065/jharma.v2i1.787

seseorang karena berkesan kurang menjaga kebersihan. Terlebih, penderita akan merasa tak nyaman sebab akan terasa gatal di bagian kulit yang terkena kurap tersebut.

Fungi (jamur) merupakan salah satu mikroorganisme penyebab penyakit pada manusia. Penyakit yang disebabkan fungi pada manusia disebut mikosis, dibagi atas mikosis superfisial dan mikosis sistemik. Mikosis superfisial merupakan mikosis yang menyerang kulit, kuku, dan rambut. Sedangkan mikosis sistemik merupakan mikosis yang menyerang jaringan/organ dalam tubuh, seperti jaringan sub-cutan, paru-paru, ginjal, jantung, mukosa mulut, usus, dan vagina. Umumnya disebabkan oleh tiga generasi fungi yaitu Trichophyton, Microsporum, dan Epidermophyton.

Salah satu alternatif dalam pengobatan infeksi kulit yang disebabkan oleh jamur adalah dengan penggunaan tanaman yang memiliki khasiat antijamur. Tanaman obat yang dapat digunakan untuk mengobati infeksi kulit akibat jamur salah satunya yaitu daun biduri (Calotropis gigantea L.).

Di Indonesia tanaman biduri (Calotropis gigantea L.) belum banyak dimanfaatkan, khususnya di daerah Aceh. Di daerah Aceh, tanaman biduri menjadi salah satu tanaman yang terabaikan. Tanaman biduri tumbuh secara liar dan dianggap gulma atau tanaman pengganggu. Padahal tanaman biduri banyak mengandung fitokimia yang bermanfaat bagi kesehatan.

Menurut Witono (2009), tanaman biduri (Calotropis gigantea L.) merupakan salah satu tanaman yang dapat digunakan sebagai antifungi yang penyebarannya terdapat di seluruh Indonesia. Tumbuhan ini termasuk dalam family Asclepiadecae. Banyak kandungan fitokimia dari berbagai bagian Calotropis gigantea L. terutama pada daun. Kandungan fitokimianya berupa tannin, saponin, flavonoid dan polifenol.

Menurut Watson dan Preedy (2007), tannin adalah senyawa aktif yang berperan sebagai antifungi, mekanisme antifungi yang dimiliki tannin adalah karena kemampuannya menghambat sintesis khitin yang digunakan untuk pembentukan dinding sel pada fungi dan merusak membran sel sehingga pertumbuhan fungi terhambat. Tannin merupakan senyawa yang bersifat lipofilik sehingga mudah terikat pada dinding sel jamur dan mengakibatkan kerusakan dinding sel jamur. Saponin, flavonoid dan polifenol adalah senyawa antioksidan alami dan zat antiinflamasi yang akan menyembuhkan peradangan pada kulit akibat infeksi fungi dan juga berperan untuk mematikan zat-zat asing dalam tubuh termasuk fungi penyebab penyakit kulit.

\section{METODOLOGI PENELITIAN}

Penelitian ini dilakukan melalui uji eksperimental laboratorium dengan menggunakan metode difusi untuk melakukan pengujian daya hambat ekstrak daun biduri terhadap Trichophyton mentagrophytes. Penelitian ini dilakukan di Laboratorium Mikrobiologi Fakultas Tarbiyah Universitas Islam Negeri Ar-Raniry Banda Aceh dan Laboratorium Kimia FKIP Kimia Universitas Syiah Kuala. Populasi dalam penelitian ini adalah tanaman biduri yang terdapat di wilayah Desa Baet, Kecamatan Baitussalam, Kabupaten Aceh Besar. Sampel dalam penelitin ini adalah daun biduri yang diperoleh di perkarangan rumah salah seorang warga di Desa Baet, Kecamatan Baitussalam, Kabupaten Aceh Besar.

Teknik pengambilan sampel diambil secara purposive sampling yaitu secara tunjuk langsung dari beberapa tanaman biduri. Daun yang diambil adalah daun utuh yang berwarna hijau, tidak kecoklatan dan tidak kekuningan dengan ukuran yang seragam.

\section{HASIL DAN PEMBAHASAN}

Berdasarkan penelitian yang telah dilakukan tentang uji efek antifungi ekstrak daun biduri terhadap pertumbuhan jamur Trichophyton mentagrophytes diperoleh diameter rata-rata dari perlakuan pertama hingga pengulangan ke tiga yaitu :

Tabel 1. Hasil zona hambat rata-rata ekstrak daun biduri (Calotropis gigantea L.) terhadap Trichophyton mentagropites

\begin{tabular}{llccccc}
\hline No & Perlakuan & $\begin{array}{c}\text { P1 } \\
(\mathrm{mm})\end{array}$ & $\begin{array}{c}\text { P2 } \\
(\mathrm{mm})\end{array}$ & $\begin{array}{c}\text { P3 } \\
(\mathrm{mm})\end{array}$ & $\begin{array}{c}\text { Rata-rata } \\
(\mathrm{mm})\end{array}$ & Kategori \\
\hline 1 & Konsentrasi 20\% & 8,5 & 7 & 9 & 8,16 & Sedang \\
2 & Konsentrasi 35\% & 8,5 & 10 & 7,5 & 8,66 & Sedang \\
3 & Konsentrasi 50\% & 9 & 9,5 & 9 & 9,16 & $\begin{array}{c}\text { Sedang } \\
4\end{array}$ \\
Aquadest & 0 & 0 & 0 & 0 & Tidak ada aktivitas \\
5 & Ketoconazole & 12,5 & 10,5 & 11,5 & 11,83 & Kuat \\
& Suspensi & & & & & \\
\hline
\end{tabular}

(Sumber: Hasil penelitian 2018) 
Journal of Pharmaceutical and Health Research

\author{
Vol 2, No 1, Februari 2021, pp. 8-11 \\ ISSN 2721-0715 (media online) \\ DOI 10.47065/jharma.v2i1.787
}

Dari tabel di atas dapat dilihat bahwa ekstrak daun biduri (Calotropis gigantea) pada konsentrasi 20\%, 35\%, dan $50 \%$ bersifat menghambat pertumbuhan jamur Trichophyton mentagrophytes dengan diameter rata-rata zona hambat secara berurutan $8,16 \mathrm{~mm}, 8,66 \mathrm{~mm}$ dan $9,16 \mathrm{~mm}$. Sedangkan diameter rata-rata zona hambat ketoconazole suspensi sebagai kontrol positif yaitu 11,83 mm termasuk dalam kategori kuat, dan aquadest sebagai kontrol negatif yaitu 0 mm termasuk dalam kategori lemah.

Penelitian dilakukan pada tanggal 26 April sampai 21 Agustus 2018 di Laboratorium Mikrobiologi Fakultas Tarbiyah Universitas Islam Negeri Ar-Raniry dan Laboratorium Kimia FKIP Kimia Universitas Syiah Kuala Banda Aceh. Sampel yang digunakan yaitu daun biduri (Calotropis gigantea L.) yang diperoleh di Desa Baet Aceh Besar. Daun biduri sebanyak $1 \mathrm{~kg}$ dikeringkan kemudian dihaluskan hingga diperoleh 100 gram serbuk kering, setelah itu direndam dengan etanol $96 \%$ sebanyak $750 \mathrm{ml}$ selama tiga hari terlindung dari cahaya, sambil sesekali diaduk. Setelah tiga hari, disaring dengan menggunakan corong kaca yang dilapisi kertas saring sehingga ampas dan filtratnya terpisah. Selanjutnya ditambahkan sisa pelarut etanol $96 \%$ sebanyak $250 \mathrm{ml}$ ke dalam ampas direndam kembali selama dua hari terlindung dari cahaya matahari. Setelah dua hari, disaring kemudian digabungkan dengan filtrat pertama dan diuapkan menggunakan vacum rotary evaporator pada suhu $\pm 40^{\circ} \mathrm{C}$ sampai diperoleh ekstrak kental sebanyak $30 \mathrm{ml}$.

Penelitian uji efek antifungi ekstrak daun biduri (Calotropis gigantea L.) terhadap pertumbuhan jamur Trichophyton mentagrophytes ini dilakukan dengan metode difusi disc diffusion, yaitu metode yang menentukan aktifitas agen antifungi. Piringan yang berisi agen fungi diletakkan pada media agar tersebut. Area jernih mengidentifikasi adanya hambatan pertumbuhan mikroorganisme oleh agen antifungi pada permukaan media agar.

Pada penelitian ini digunakan jamur Trichophyton mentagropythes yang dibiakkan pada media PDA (Potato Dextrose Agar), kemudian dibuat suspensi sebanding Mc. Farland standar dan dilanjutkan penanaman ke media PDA dengan menggunakan batang bengkok untuk meratakan jamur pada media tersebut. Antifungi yang digunakan pada penelitian ini adalah ketoconazole.

Menurut Rushing (2009), ketoconazole merupakan antifungi yang mempunyai spektrum antimikotik yang efektif terhadap dermatofit dan ragi. Ketoconazole adalah antifungi azole turunan imidazole sintesis obat ini bekerja dengan menghambat kerja enzim sitokrom p450 pada membran sel fungi, sehingga mengganggu sintesa ergosterol yang merupakan komponen penting dari membran sel fungi. Dengan mekanisme kerjanya tersebut, ketoconazole dapat menyebabkan kerusakan pada membran sel fungi, obat ini memiliki aktifitas antimikotik luas terhadap fungi jenis Tricophyton Sp. Ketoconazole yang digunakan dalam bentuk suspensi, yang dibuat dengan cara ditimbang Na CMC sebanyak 1 gram kemudian ditambahkan aquadest yang sudah dipanaskan sedikit demi sedikit sebanyak $20 \mathrm{ml}$, digerus kuat hingga terbentuk korpus suspense lalu ditambahkan tablet ketoconazole $200 \mathrm{mg}$ yang sudah digerus terlebih dahulu kemudian ditambahkan aquadest yang sudah dipanaskan sampai $100 \mathrm{ml}$ digerus sampai homogen.

Hasil penelitian menunjukan bahwa pemberian ekstrak daun biduri (Calotropis gigantea L.) pada Trichophyton mentagrophytes dapat mempengaruhi pertumbuhan jamur tersebut.

Hasil penelitian yang menujukkan bahwa daun biduri (Calotropis gigantea L.) mempunyai aktifitas untuk menghambat pertumbuhan jamur Trichophyton mentagrophytes, karena kandungan senyawa kimia yang terdapat pada daun biduri seperti tannin mampu menghambat sintesis khitin yang digunakan untuk pembentukan dinding sel pada fungi dan merusak membrane sel sehingga prtumbuhan fungi terhambat. Saponin, flavonoid dan polifenol adalah senyawa antioksidan dan zat antiinflamsi yang akan menyembuhkan peradangan pada kulit akibat infeksi fungi dan juga berperan untuk mematikan zat-zat asing dalam tubuh termasuk fungi.

Uji diameter zona hambat ekstrak daun biduri dilakukan dengan mengamati diameter hambat yang terbentuk setelah diinkubasi pada suhu $37^{\circ} \mathrm{C}$ selama 24 jam. Konsentrasi ekstrak daun biduri yang digunakan yaitu $20 \%$, $35 \%$ dan $50 \%$ yang dilakukan pengulangan sebanyak $3 \mathrm{kali}$, dan setiap pengulangan terdapat diameter yang berbeda-beda. Pada konsentrasi $20 \%$ sebesar 8,16 mm termasuk dalam kategori sedang, konsentrasi 35\% sebesar 8,66 mm termasuk dalam kategori sedang, konsentrasi 50\% sebesar 9,16 mm termasuk dalam kategori sedang, pada kontrol positif dengan menggunakan antijamur ketoconazole sebesar 11,83 $\mathrm{mm}$ termasuk dalam kategori kuat dan aquadest sebagai kontrol negatif tidak memiliki daya hambat terhadap jamur Trichophyton mentagrophytes.

\title{
4. KESIMPULAN
}

Berdasarkan hasil penelitian uji efek antifungi ekstrak daun biduri (Calotropis Gigantea L.) terhadap pertumbuhan jamur Trichophyton mentagrophytes dapat disimpulkan bahwa eEkstrak daun biduri (Calotropis Gigantea L.) dapat menghambat pertumbuhan jamur Trichophyton Mentagrophytes. Konsentrasi optimal ekstrak daun biduri (Calotropis gigantea L.) dalam menghambat pertumbuhan jamur Trichophyton Mentagrophytes yaitu pada konsentrasi 50\% dengan diameter hambat sebesar 9,16 mm dan termasuk diameter terbesar 


\section{Journal of Pharmaceutical and Health Research \\ Vol 2, No 1, Februari 2021, pp. 8-11 \\ ISSN 2721-0715 (media online) \\ DOI 10.47065/jharma.v2i1.787 \\ DAFTAR PUSTAKA}

Amiit J, dkk. (2010). Phytochemistry and Evaluation of Antioxidant Activity of Whole Plant of Calotropis gigantea Linn. International Journal of Research Ayurveda and Pharmacy

Darwis, D. (2000). Teknik Dasar Laborotarium dalam Penelitian Senyawa Bahan Alam. Padang: Universitas Andalas.

Indrayatna (2010). Penerbit Buku. Kedokteran EGC. Penyakit kulit, tanda dan gejala, cara penularan, dampak dan upaya pencegahan. Jakarta

Jawetz, E, j. dkk., (2004). Mikrobiologi Kedokteran. Buku Kedokteran EGC: Jakarta

Jawetz, E, J. dkk., (2005). Mikrobiologi Kedokteran Edisi 23, EGC: Jakarta

Pratiwi, S.T. (2008). Mikrobiologi Farmasi. Erlangga PT. Gelora Aksara: Jakarta.

Munawarah, R. (2016). Uji Aktifitas Antijamur Jamu Madura "Empot Super" terhadap Jamur Candida albicans. Malang

Rushing ME. (2009). Tinea corporis, US: Medical College Of georginia.

Shirsat, dkk. (2009). Histological Study of Different Part of Calotropis gigantea Linn. Journal of Global Technology

Sastroamidjojo, S. (2007). Obat Asli Indonesia. Jakarta: Dian Rakyat

United States Departement of Agriculture. (2010) Http://plants.usda.gov [Diakses tanggal 1 Oktober 2017].

Witono Y. (2009). Spesifitas dan Stabilitas Enzim Protase dari Tanaman Biduri (Calotropis gigantea L). Prosiding Seminar Nasional

Watson R. R. dan Preedy, V. R. (2007). Bioactive Foods In Promoting Health: Probioticts and Prebioticts. Academic Press. US A 